\title{
Correction to: Inter-patient detection of atrial fibrillation in short ECG segments based on LSTM network with multiple input layers
}

\author{
Rafael Pereira ${ }^{1}$ (1) $\cdot$ Rodrigo Varejão Andreão ${ }^{2}$ (1)
}

Published online: 2 March 2022

(c) Sociedade Brasileira de Engenharia Biomedica 2022

Correction to: Res. Biomed. Eng. https://doi.org/10.1007/s42600-022-00198-z

In Eqs. 1 and 2 of the article, in the term "D-RR," the dash was by mistake converted to the Greek letter lambda.

The original article has been corrected.

Publisher's note Springer Nature remains neutral with regard to jurisdictional claims in published maps and institutional affiliations.

The online version of the original article can be found at https:// doi.org/10.1007/s42600-022-00198-z

Rafael Pereira

rafael0prr@gmail.com

1 Av. Santa Leopoldina 1200, Vila Velha, ES 29102-901,

Brazil

2 Department of Electrical Engineering, Instituto Federal do Espírito Santo, Av. Vitória, 1729, Vitória, ES 29040-780, Brazil 